\title{
sciendo
}

\section{INBREEDING IN A POPULATION OF POLISH HOLSTEIN-FRIESIAN YOUNG BULLS BEFORE AND AFTER GENOMIC SELECTION*}

\author{
Piotr Topolski ${ }^{1 *}$, Wojciech Jagusiak ${ }^{2}$ \\ 'Department of Genetics and Cattle Breeding, National Research Institute of Animal Production, \\ 32-083 Balice n. Kraków, Poland \\ ${ }^{2}$ Department of Genetics and Animal Breeding, Faculty of Animal Science, University of Agriculture \\ in Krakow, Al. Mickiewicza 24/28, 31-059 Kraków, Poland \\ •Corresponding author: piotr.topolski@izoo.krakow.pl
}

\begin{abstract}
Inbreeding was analysed in a population of 14,144 Polish Black-and-White Holstein-Friesian (PBWHF) young bulls born between 1994 and 2017 and bred under both conventional and genomic breeding programmes. The inbreeding coefficients were computed using a model with genetic groups, according to the algorithm given by VanRaden. It was found that in the analysed population all bulls are inbred $(100 \%$ of the population), with the mean coefficient of inbreeding ranging from $0.09 \%$ to $26.95 \%$. Pedigree analysis also showed a relationship between the changing number of bulls over the years and the dynamics of population inbreeding. These trends are connected with changes in the breeding scheme, related to the implementation of genomic selection in the breeding programme for PBWHF cattle in 2014. The increasing number of weaned young bulls in Poland was paralleled by a fairly consistent increase in the mean inbreeding, but the inbreeding dynamics were relatively small. A reverse trend was observed in the group of young bulls born after 2013. As the number of bulls very rapidly decreased in successive birth years, the mean inbreeding for successive birth-year groups very rapidly increased. As a result, the estimated linear trend was equal to $0.02 \%$ inbreeding per year of birth in the group of bulls raised before genomic selection $(\sim 20$ birth-year) whereas in the group of bulls raised after genomic selection ( $\sim 4$ birth-year) the trend was much higher and amounted to $0.56 \%$ inbreeding per year of birth. The high mean inbreeding found in the group of the genomically selected young bulls may translate into higher inbreeding in the whole population of PBWHF cattle, because these bulls are now intensively used as sires. The results of our study also show that the implementation of genomic selection in the breeding programme caused a very rapid increase in the inbreeding rate per birth-year in young bulls.
\end{abstract}

Key words: inbreeding, genomic selection, pedigree, bull, cattle

The contribution of sires to genetic progress is crucial due to the intensive use of artificial insemination, which allows for a large number of progeny per sire. Over the

\footnotetext{
*Work performed as part of the multi-year program: project no. 03-17-17-09.
} 
last decades, this has considerably accelerated breeding progress, thus increasing the effectiveness of breeding programmes (Strabel, 2001; Topolski and Jagusiak, 2011; Topolski 2017). On the other hand, the widespread use of artificial insemination makes it possible to use a small number of the best bulls in breeding, which may be related. An increase in the relatedness of a population generally leads to undesirable changes in its genetic structure and contributes to increasing the mean inbreeding (Croquet et al., 2006; Pavlik et al., 2019). In turn, a decrease in the mean degree of heterozygosity within a population is almost always paralleled by greater inbreeding depression, which is manifested by a decrease in the mean genetic and phenotypic value of quantitative traits (Parland et al., 2007; Bjelland at al., 2013; Topolski and Jagusiak, 2012; Topolski, 2017). This decline in the population of Holstein-Friesian (HF) cattle has been well documented in the literature (Miglior et al., 1995; Smith et al., 1998; Thompson et al., 2000; Strabel, 2001; Wall et al., 2005; Sewalem et al., 2006; Parland et al., 2007; Panetto et al., 2010; Bjelland at al., 2013; Howard et al., 2017). The negative effects of inbreeding depression are also found in populations of other species of animals (Różańska-Zawieja et al., 2013; Świderek et al., 2015; Polak, 2019).

As it appears from the above, the high level of inbreeding in the female part of the population of cattle translates directly into inbreeding depression associated with a reduction in the values of production and functional traits. The increasing degree of homozygosity in the male part of the population - suggesting a high average relationship between groups of breeding animals from which dams and sires of bulls are selected - does not lead to a decrease in productivity, but indicates a systematically decreasing genetic diversity in their population. The use of these bulls in reproduction in the long term reduces genetic variability also in the cow population (Topolski, 2017). Until recently, it was considered that the problem of increased inbreeding mainly concerns American subpopulations of HF cattle, but it is also becoming more serious in the European populations due to the "Holsteinization" (i.e., the use of a relatively small number of related HF bulls by crossbreeding with Blackand-White cattle) that has taken place in Europe in recent decades (Kania-Gierdziewicz, 2005; Sewalem et al., 2006; Sorensen et al., 2006; Parland et al., 2007; Pavlik et al., 2019). In Poland, the widespread use of imported bull semen started in 1971 (Trela et al., 1995). Filistowicz (1977) reported that already in the 1970s in Lower Silesia, breeding lines and related groups were created based on imported bulls, which were more numerous and more intensively used compared to domestic sires. Although the process of "Holsteinization" has largely ended in Poland, the import of HF sires of North American origin further contributes to the increase of inbreeding.

In practice, the undesirable consequences of the high mean inbreeding of a population are limited by the use of planned, individual matings. The Polish Federation of Cattle Breeders and Dairy Farmers recommends that individually mated cows and bulls have no common ancestors back two generations (PFHBiPM, 2018).

The objective of the study was to investigate changes in inbreeding of the population of Polish Holstein-Friesian young bulls born over 23 years (about 4 generations) and bred under both conventional and genomic breeding programmes. 


\section{Material and methods}

The material used in this study consisted of the pedigrees of 14,144 Polish Holstein-Friesian (PHF) young bulls. The file comprised all young bulls raised in Poland and born between 1994 and 2013, evaluated and pre-selected based on their individual performance (IEB) and genomically evaluated young bulls (GEB) born between 2013 and 2017 (year 2017 includes only bulls with estimated breeding value in 2/2018 and born in early 2017). Only bulls of the Black-and-White strain were included in the file. The IEB and GEB bulls represent a kind of elite group of animals in the structure of the National Breeding Programme of the PHF breed, because they come from planned matings of parents with known origin and high breeding values. Therefore, they are candidates for sires of dams and sires of future generations. The IEB bulls were obtained as a result of the implementation of the breeding programme up to 2013. The young bulls (GEB) are the result of the implementation of a breeding programme based on genomic selection, implemented in Poland since 2014. Basic pedigree information was augmented with data from the Polish Federation of Cattle Breeders and Dairy Farmers' Pedigree File of Bulls. The final file contained the ID numbers of 73,159 animals.

When constructing a pedigree file that contained original animal ID numbers (numbers from the country of first registration), date of birth, sex, and barn ID, use was made of an original program written in Fortran 95, which makes it possible to approximate birth years for animals without this information and to check the birth years and sex of other animals for accuracy. This program was also used to determine the degree of pedigree completeness shown in Figure 1.

The pedigree file was used to calculate the inbreeding coefficients using the "PEDIG 2007" package (Boichard, 2007). The inbreeding coefficient was computed using a model with genetic groups, according to the algorithm developed by VanRaden. Genetic groups were created using the rules specified by Westell et al. (1988). In this approach, unknown parents are assigned to groups on the basis of sex and generation. Finally, a total of 32 groups were created - 16 for unknown sires and 16 for unknown dams.

The means and standard deviations for inbreeding coefficients within years were calculated with $\mathrm{R}$ packages.

Linear regression and third order polynomials were used to determine trends in the number of bulls raised in Poland and the mean inbreeding of the population.

\section{Results}

Figure 1 shows the average pedigree completeness index per birth year of Polish Black-and-White Holstein-Friesian young bulls including the first 4, 6 and 10 generations of ancestors. The degree of pedigree completeness for the first 4 generations of ancestors for all birth-years of bulls was close to $100 \%$ and ranged from $97.30 \%$ in 2000 to $99.83 \%$ in 2013 and 2016. Average pedigree completeness indexes per 
birth year of bulls for further generations of ancestors (the first 6 and first 10) were $87.44 \%$ and $59.62 \%$ and increased from $80.38 \%$ and $45.69 \%$ in 1994 to $95.96 \%$ and $78.39 \%$ in 2016 , respectively.

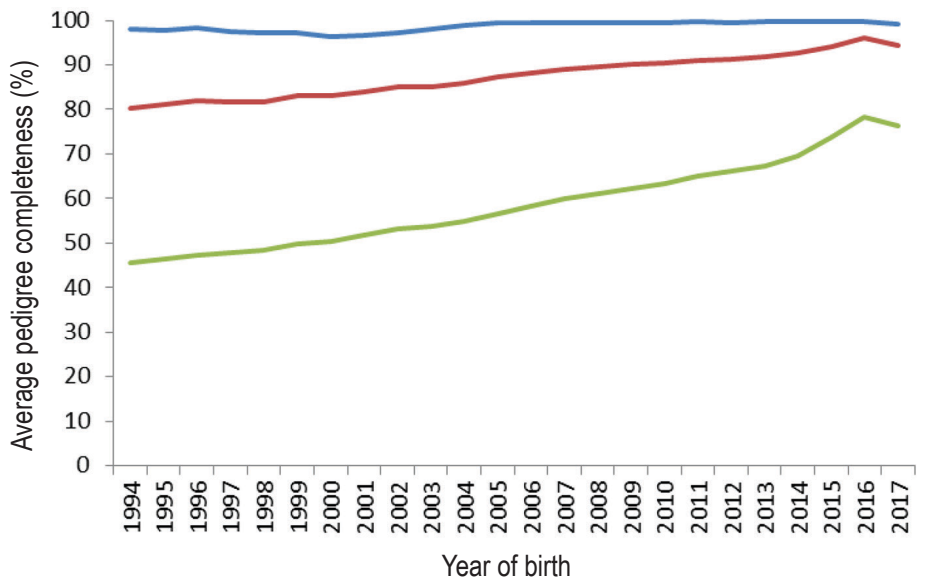

Figure 1. Average pedigree completeness index per birth year of Polish Black-and-White Holstein-Friesian young bulls including the first 4 (blue line), 6 (red line) and 10 (green line) generations of ancestors

Table 1 presents inbreeding characteristics for the population of PHF bulls according to year of birth. In the analysed population including a total of 14144 bulls, the mean coefficient of inbreeding was $1.58 \%$ and ranged from $0.09 \%$ to $26.95 \%$. In groups of IEB bulls this coefficient increased irregularly from $1.25 \%$ for animals born in 1994 to $1.75 \%$ for animals born in 2013. In groups of GEB bulls, the mean inbreeding coefficients increased quite appreciably from $2.13 \%$ for bulls born in 2014 to $3.78 \%$ for bulls born in 2017. Compared to the group of IEB bulls, this group of bulls also had higher minimum values of the inbreeding coefficient, which were $0.66 \%, 0.55 \%, 0.74 \%$ and $0.78 \%$ for animals born in 2014, 2015, 2016 and 2017, respectively.

Table 1. Descriptive characteristics of inbreeding in the population of Polish Black-and-White Holstein-Friesian young bulls depending on year of birth

\begin{tabular}{l|c|c|c|c|c}
\hline \multirow{2}{*}{ Year of birth } & \multirow{2}{*}{$\mathrm{N}$} & \multicolumn{4}{|c}{ Coefficient of inbreeding (\%) } \\
\cline { 3 - 6 } & & $\overline{\mathrm{x}}$ & $\mathrm{SD}$ & $\min$ & $\max$ \\
\hline 1 & 2 & 3 & 4 & 5 & 6 \\
\hline 1994 & 65 & 1.25 & 0.91 & 0.24 & 4.03 \\
1995 & 452 & 1.42 & 1.17 & 0.11 & 6.39 \\
1996 & 462 & 1.72 & 1.64 & 0.12 & 1.53 \\
1997 & 446 & 1.47 & 1.55 & 0.11 & 12.88 \\
1998 & 430 & 1.39 & 1.34 & 0.10 & 8.11 \\
\hline
\end{tabular}


Table 1 - contd.

\begin{tabular}{lrrrrrr}
\hline & 1 & 2 & 3 & 4 & 5 & 6 \\
\hline 1999 & 265 & 1.31 & 1.39 & 0.10 & 7.58 \\
2000 & 341 & 1.62 & 1.46 & 0.09 & 9.94 \\
2001 & 335 & 1.80 & 2.06 & 0.10 & 25.29 \\
2002 & 385 & 1.70 & 1.60 & 0.17 & 14.96 \\
2003 & 491 & 1.61 & 1.78 & 0.15 & 26.95 \\
2004 & 733 & 1.59 & 1.43 & 0.11 & 13.47 \\
2005 & 1014 & 1.50 & 1.24 & 0.15 & 13.45 \\
2006 & 937 & 1.66 & 1.51 & 0.19 & 26.06 \\
2007 & 1040 & 1.68 & 1.31 & 0.17 & 13.86 \\
2008 & 1098 & 1.64 & 1.17 & 0.22 & 13.36 \\
2009 & 1101 & 1.69 & 1.35 & 0.14 & 25.15 \\
2010 & 1036 & 1.73 & 1.29 & 0.26 & 14.03 \\
2011 & 1221 & 1.75 & 1.34 & 0.18 & 14.14 \\
2012 & 1285 & 1.71 & 1.08 & 0.30 & 14.39 \\
2013 & 801 & 1.75 & 1.32 & 0.35 & 16.11 \\
2014 & 63 & 2.13 & 1.27 & 0.66 & 6.58 \\
2015 & 76 & 2.69 & 2.12 & 0.55 & 0.74 \\
2016 & 55 & 3.35 & 1.52 & 0.78 & 15.15 \\
2017 & 12 & 3.78 & 3.72 & & 06 \\
\hline
\end{tabular}

Table 2. Frequency of Polish Black-and-White Holstein-Friesian young bulls depending on year of birth and coefficient of inbreeding

\begin{tabular}{l|c|c|c|c|c|c|c}
\hline \multirow{2}{*}{ Year of birth } & \multicolumn{7}{c}{ Coefficient of inbreeding (\%) } \\
\cline { 2 - 8 } & 0 & $>0-1$ & $>1-2$ & $>2-3$ & $>3-6$ & $>6-18$ & $>18-30$ \\
\hline 1 & 2 & 3 & 4 & 5 & 6 & 7 & 8 \\
\hline 1994 & 0.000 & 0.815 & 0.123 & 0.031 & 0.031 & 0.000 & 0.000 \\
1995 & 0.000 & 0.746 & 0,168 & 0.022 & 0.060 & 0.004 & 0.000 \\
1996 & 0.000 & 0.660 & 0.186 & 0.054 & 0.082 & 0.017 & 0.000 \\
1997 & 0.000 & 0.632 & 0.204 & 0.065 & 0.081 & 0.018 & 0.000 \\
1998 & 0.000 & 0.630 & 0.198 & 0.063 & 0.102 & 0.007 & 0.000 \\
1999 & 0.000 & 0.664 & 0.192 & 0.042 & 0.087 & 0.015 & 0.000 \\
2000 & 0.000 & 0.513 & 0.217 & 0.150 & 0.106 & 0.015 & 0.000 \\
2001 & 0.000 & 0.427 & 0.293 & 0.143 & 0.110 & 0.024 & 0.003 \\
2002 & 0.000 & 0.364 & 0.382 & 0.138 & 0.096 & 0.021 & 0.000 \\
2003 & 0.000 & 0.424 & 0.352 & 0.106 & 0.098 & 0.018 & 0.002 \\
2004 & 0.000 & 0.438 & 0.318 & 0.117 & 0.108 & 0.019 & 0.000 \\
2005 & 0.000 & 0.422 & 0.365 & 0.116 & 0.085 & 0.012 & 0.000 \\
2006 & 0.000 & 0.348 & 0.398 & 0.145 & 0.097 & 0.011 & 0.001 \\
2007 & 0.000 & 0.313 & 0.442 & 0.136 & 0.096 & 0.013 & 0.000 \\
\hline
\end{tabular}


Table 2 - contd.

\begin{tabular}{l|c|c|c|c|c|c|c}
\hline & 2 & 3 & 4 & 5 & 6 & 7 & 8 \\
\hline 2008 & 0.000 & 0.293 & 0.466 & 0.155 & 0.079 & 0.006 & 0.000 \\
2009 & 0.000 & 0.267 & 0.476 & 0.170 & 0.078 & 0.008 & 0.001 \\
2010 & 0.000 & 0.248 & 0.508 & 0.141 & 0.089 & 0.014 & 0.000 \\
2011 & 0.000 & 0.233 & 0.522 & 0.145 & 0.080 & 0.020 & 0.000 \\
2012 & 0.000 & 0.208 & 0.534 & 0.172 & 0.077 & 0.009 & 0.000 \\
2013 & 0.000 & 0.222 & 0.531 & 0.161 & 0.070 & 0.016 & 0.000 \\
2014 & 0.000 & 0.175 & 0.381 & 0.238 & 0.190 & 0.016 & 0.000 \\
2015 & 0.000 & 0.039 & 0.395 & 0.276 & 0.263 & 0.026 & 0.000 \\
2016 & 0.000 & 0.018 & 0.164 & 0.291 & 0.473 & 0.055 & 0.000 \\
2017 & 0.000 & 0.083 & 0.083 & 0.417 & 0.333 & 0.083 & 0.000 \\
TOTAL & 0.000 & 0.361 & 0.403 & 0.133 & 0.089 & 0.013 & $\sim 0.000$ \\
\hline
\end{tabular}

Table 2 shows the frequency of bulls depending on the inbreeding coefficient and year of birth. In the analysed population, almost $36 \%$ are bulls with a low coefficient of inbreeding (less than 1\%). Bulls with an inbreeding coefficient of $1 \%$ to $3 \%$ constitute almost $40 \%$ of the entire population. The highest coefficients of inbreeding, from $6 \%$ to $18 \%$ and from $18 \%$ to $30 \%$, were found for $1.35 \%$ and $0.03 \%$ of the population, respectively. For subsequent birth-year groups, the number of bulls with higher coefficients of inbreeding in general increased quite regularly per birth year.

Trends in the number of young bulls raised in Poland and the mean inbreeding of their population are shown in Figure 2.

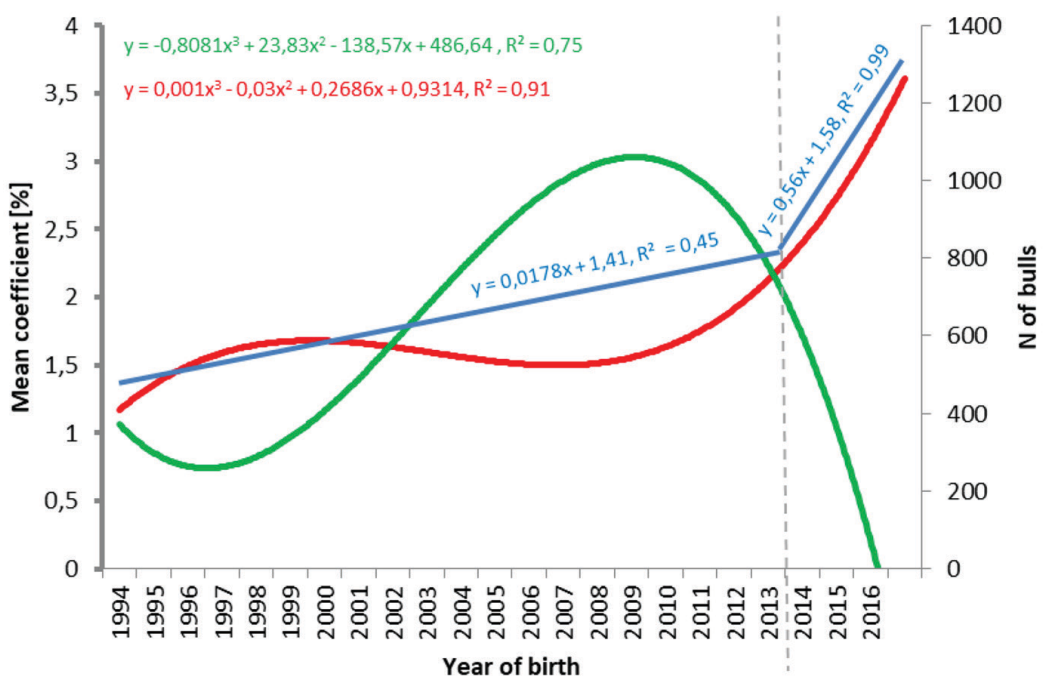

Figure 2. Trend lines (polynomial - red and linear regression - blue) for the mean coefficient of inbreeding and the number (polynomial - green) of Polish Black-and-White Holstein-Friesian young bulls 


\section{Discussion}

In the analysed population almost $100 \%$ average completeness of pedigree was found in the first four generations of ancestors for all birth-years of bulls, which has a highly significant impact on the accuracy of calculating the recent inbreeding (Gurgul et al., 2016; Topolski, 2017). In turn, considering further generations of ancestors, there was found to be a tendency for the average completeness of pedigree to increase along with successive birth-years of bulls. Therefore, the coefficients of inbreeding for the analysed bull population were computed using a model with genetic groups according to VanRaden's algorithm (VanRaden, 1992). Studies by many authors (VanRaden, 1992; Wiggans et al., 1995; Lutaaya, 1999; Jagusiak and Żarnecki, 2002; Gurgul et al., 2016; Sell-Kubiak et al., 2018) have shown that the use of this method for genealogical analysis of dairy cattle increases the accuracy of the inbreeding coefficients, especially when pedigrees are incomplete. The inbreeding coefficients estimated from incomplete pedigrees may be underestimated because some relationships among ancestors may not be included (VanRaden, 1992; Wiggans et al., 1995; Cassell et al., 2003). Lutaaya (1999) showed that the mean inbreeding coefficient calculated using a model with genetic groups is higher than the inbreeding coefficient calculated using the conventional method (Meuwissen and Luo, 1992), but the difference decreases as pedigrees become more complete.

In Poland, the quality of pedigree information in the dairy cattle population could have been affected by the Holsteinization process, whereby the HF breed was used for intensive crossing with the domestic population of dairy cattle (Jagusiak and Żarnecki, 1994; Trela et al., 1995). As noted above, in recent decades Holsteinization has introduced large amounts of imported genetic material into the Polish cattle population (Jagusiak and Żarnecki, 1994; Kania-Gierdziewicz, 2005). On the other hand, the use of so many imported bulls in domestic breeding might have contributed to the introduction of a considerable number of animals with incomplete pedigrees (Jagusiak and Żarnecki, 1994).

The appropriateness of using the model with genetic groups in pedigree analysis of the Polish dairy cattle population is directly confirmed by the findings of Jagusiak and Ptak (2003), who compared inbreeding coefficients calculated using VanRaden and conventional methods for the Polish population of Black-and-White cattle with different percentages of HF genes. The comparisons were made with multigenerational populations of bulls born between 1978 and 1997 and with cows born between 1989 and 1999. The authors demonstrated that the first method produced higher inbreeding coefficients compared to the conventional method.

Based on the pedigree analysis, it should be noted that the analysed bull population is characterized by a large number of inbred animals, which constitute $100 \%$ of the population. The majority of animals are characterized by a low inbreeding coefficient $(<2 \%)$, but in some bulls this coefficient ranged from $6 \%$ to $18 \%$, and in others as much as $18 \%$ to $30 \%$. Such high inbreeding is achieved by mating closely related animals, and, in the case of the coefficients falling within the latter range, even as a result of incestuous breeding. The mating of such closely related animals, in par- 
ticular incestuous mating, is considered to be a considerable error in dairy breeding (Miglior et al., 1995; Sewalem et al., 2006).

The mean inbreeding coefficient in the bull population is relatively low (1.58\%), ranging from $0.09 \%$ to $26.95 \%$. The low inbreeding coefficients obtained in this study are higher than the coefficients reported before for the Polish populations of Black-and-White and PBWHF bulls (Jagusiak and Żarnecki, 1994, 2002; Kania-Gierdziewicz, 2005). This concerns inbreeding coefficients calculated with the conventional method and with a method based on the algorithm of VanRaden (Jagusiak and Ptak, 2003) and confirms a steady increase in the mean inbreeding of the PBWHF cattle population.

The mean inbreeding coefficient, calculated by Kania-Gierdziewicz (2005), for the Polish population of AI bulls was $0.28 \%$. The same author also showed that the mean inbreeding of the bulls increased with the increasing percentage of HF genes in the genotype. The mean inbreeding coefficient was $0.17 \%$ for purebred Black-andWhite bulls and $0.6 \%$ for purebred HF bulls.

Young and Seykora (1996) analysed inbreeding coefficients depending on the base year using a random sample of 600 US Holstein-Friesian cows. They considered the animals born in the base year as unrelated and noninbred. The mean inbreeding coefficient in cows born in 1990 decreased from $5.08 \%$ to $1.75 \%$ as the base moved from 1884 to 1960 . A base year of 1950 gave a quadrupling of inbreeding estimates from 1970 to 1990 . The same authors stated that the annual rate of increase in inbreeding, which ranged from $0.09 \%$ to $0.11 \%$ and depended little on the base year, was much better in describing the rate of inbreeding changes in the population compared to the mean coefficients.

Jagusiak and Ptak (2003) found that the inbreeding increase in the Polish population of Black-and-White cattle with different HF percentages is small $(0.04 \%$ per year), and the highest inbreeding coefficients (close to $0.6 \%$ ), computed for the youngest bulls, are three times as low as mean inbreeding in the US populations. The same authors considered that a slow but steady increase in the inbreeding level of the domestic cattle population may make it necessary to include inbreeding in the model for estimating breeding values. In the population of PBWHF bulls, the mean inbreeding rate was found to be increasing much more rapidly. The mean inbreeding coefficient increased during the analysed period from $1.25 \%$ in animals born in 1994 to $3.78 \%$ in bulls born in 2017 . This means that the mean inbreeding increment in the population under analysis is $0.08 \%$ per year, which is twice as much as the value reported by Jagusiak and Ptak (2003).

In our study, the pedigree analysis of the bull population also points to a relationship between the changing number of birth-year groups and the rate of inbreeding changes in the population. The increase in the number of bulls born before 2013/2014 and raised in Poland was paralleled by a fairly consistent increase in mean inbreeding, but the dynamic in the rate of inbreeding was relatively slow. An inverse trend was observed for the group of bulls born from 2014. As the number of bulls rapidly decreased for those years of birth, the mean inbreeding very rapidly increased for successive birth-year groups. In the population of IEB young bulls born from 1994 to 2008 investigated by Topolski and Jagusiak (2011), comparable trends in the mean 
inbreeding rate and number of bulls in successive years of birth were also noted for the dynamics of mean relatedness and for the number of bulls in successive birth years. The authors interpreted this relationship as the effect of changes in breeding policy, the high volume of semen imports and selection of bull dams and sires based on the BLUP - Animal Model, which uses a relationship matrix between animals (Henderson, 1975, 1976; Topolski and Majewska, 2006; Topolski, 2008). Currently, these phenomena can be primarily interpreted as the effect of changes in breeding policy related to the introduction of genome selection assumptions for the breeding programme in 2014.

In the initial period of the implementation of genomic selection for breeding programmes in dairy cattle, there was an optimistic prognosis about the dynamics of inbreeding as the introduction of a new method in the selection of dairy cattle. Daetwyler et al. (2007) suggested that genome-wide selection reduces the rate of inbreeding per generation compared to the traditional selection method based on best linear unbiased prediction (BLUP) selection. On the other hand, in stochastic simulation studies done by De Roos et al. (2011) it was shown that genomic selection in combination with a severe reduction in the generation interval can double the rate of genetic gain at the same rate of inbreeding per generation, but with a higher rate of inbreeding per year. The authors also suggested that the number of progeny-tested bulls can be greatly reduced, although this will slightly affect the quality of the proven bull team.

Meanwhile, the results presented in our paper show that there was a very rapid decrease in the number of young bulls (most likely associated with the desire to reduce the costs of raising and genotyping bulls by breeders) and a very rapid increase in the rate of inbreeding per birth year of bulls, as a result of the implementation of a breeding programme based on genomic selection in Poland. The possibility of a significant reduction in the number of bulls in the genomic selection method resulted in the fact that dams and sires with the highest breeding values (breeding elite) were selected as young bulls' parents, but which were also more related to each other than the average relationship in the entire population.

Such a rapid increase in inbreeding in GEB bulls must have been caused by relationships between ancestors especially in the first three and to a much lesser degree in the first four generations, whereas completeness of first four generations was almost $100 \%$ for both groups of bulls (Figure 1). Although the completeness of pedigree containing further generations of ancestors was smaller for IEB bulls than for GEB ones, this could not have affected to a large extent the average inbreeding in both groups.

The increase in the inbreeding rate per birth year of Holstein cattle along with the implementation of genomic selection is also noted in other leading HF cattle populations in the world, in which there was not such a high reduction in the number of young bulls as in Poland. In a study by Forutan et al. (2018), inbreeding coefficients were calculated in a sample of genotyped North American Holstein animals born from 1990 to 2016 using $50 \mathrm{k}$ chip data and ROH patterns (FROH) and pedigree-based information (FPED) which was assessed before and after genomic selection. The authors reported that for animals born prior to 2010, before initial use of genomic young sires in North America, the average FROH increased by about 0.001 
per year, while after implementation of genomic selection average FROH increased by about 0.005 per year. The average annual increase of pedigree-based inbreeding after implementation of genomic selection was also higher (0.003 vs. 0.001). These results show that average inbreeding is increasing at a faster pace than before implementation of genomic selection in North American Holstein.

Doekes et al. (2018) investigated trends in genome-wide and region-specific genetic diversity in the Dutch-Flemish Holstein-Friesian breeding programme from 1986 to 2015 . Pedigree and genotype data ( 75.5 k) of 6280 AI-bulls were used to estimate rates of genome-wide inbreeding and kinship in these analyses. It was found that after introduction of genomic selection (around 2010), rates of inbreeding and kinship increased substantially while allele frequencies continued to change in the same direction as before genomic selection.

In our analyses, the highest mean increase of inbreeding found in the group of GEB bulls may today translate into an increase in inbreeding in the population of PBWHF cattle, because these bulls are now intensively used in breeding. In the long term, this phenomenon is very unfavourable because it will be associated with a significant reduction in genetic variance and increase the negative effects of inbreeding depression in the entire population. Therefore, there is an urgent need to develop appropriate solutions (breeding scheme) and methods of genetic improvement of dairy cattle to reduce the rate of inbreeding per birth-year and generation in the population selected using genomic selection in Poland.

One of the possible solutions for this problem is the application of the Optimum Genetic Contribution (OGC) theory to the selection of Holstein cattle in Poland. The idea of genetic contributions was first introduced by James and McBride (1958) and is currently often used in animal breeding as Optimal Contribution Selection (OCS). This method is based on maximizing genetic gain while reducing the rate of inbreeding by weighting estimated breeding values with average relationships among individuals. Many theoretical and simulation studies show that the use of OGC theory can effectively reduce the rate of inbreeding over generations with a minimal decrease of selection response in different species of farm animals, including dairy cattle (König et al., 2010; Oh, 2012). Newer results of scientific research based on simulation studies show the possibility of using this method for management of inbreeding also in genomically selected animals (Woolliams et al., 2015; Wang et. al., 2017).

Sanchez-Molano et al. (2016), based on a stochastic simulation research study, demonstrated that the use of optimum contribution strategies in a genomic context effectively reduces the rate of increase of inbreeding while ensuring genetic improvement in traits of interest, and genomic-based optimum contribution strategies can be recommended both from conservation and animal genetic improvement perspectives. In turn, the effectiveness of OCS applications on commercial data was confirmed in studies conducted by Howard et al. (2018). The authors provide some support for the assertion that there is an advantage in combining Optimal Contribution Selection with genomic information, which can achieve more accurate prediction of Mendelian sampling term at an earlier age, to generate greater genetic progress over time, without negatively impacting the rate of inbreeding. 
In conclusion, the results of our study indicate an unfavorable tendency to intensify inbreeding dynamics in the population of young bulls as the implementation of genomic selection in HF cattle breeding in Poland. The results obtained also indicate the need to calculate and analyse other parameters of the genetic structure of the population of young bulls, for a more complete knowledge of changes in the genetic diversity in the young bulls population.

\section{References}

Bjelland D., Weige 1 K., Vukasinovic N., Nkrumah J. (2013). Evaluation of inbreeding depression in Holstein cattle using whole-genome SNP markers and alternative measures of genomic inbreeding. J. Dairy Sci., 96: 4697-4706.

B o i chard D. (2007). PEDIG - a Fortran package for pedigree analysis suited for large populations. Proc. 7th World Congress on Genetics Applied to Livestock Production, Montpellier.

C a s s e 11 B., A d a m e c V., P e a r s on R. (2003). Maternal and fetal inbreeding depression for 70-day nonreturn and calving rate in Holsteins and Jerseys. J. Dairy Sci., 86: 2977-2983.

Croquet C., Mayers P., Gills on A., Vanderick S., Gengler N. (2006). Inbreeding depression for global and partial economic indexes, production, type and functional traits. J. Dairy Sci., 89: 2257-2267.

D a e tw y le r H.D., Vill a nu e va B., B i j m a P., Wo o 11 i a m s J.A. (2007). Inbreeding in genomewide selection. J. Anim. Breed. Genet., 124: 369-376.

De Roos A., Schrooten C., Veerkamp R., Van Arendonk J. (2011). Effects of genomic selection on genetic improvement, inbreeding, and merit of young versus proven bulls. J. Dairy Sci., 94: $1559-1567$.

Doekes H.P., Veerkamp R.F., Bijma P., Hiemstra S.J., Windig J.J. (2018). Trends in genome-wide and region-specific genetic diversity in the Dutch-Flemish Holstein-Friesian breeding program from 1986 to 2015. Genet. Select. Evol., 50: 15.

Filistowicz A. (1977). Genetic analysis of Red-and-White Lowland sires used in Lower Silesia. Implementation study (in Polish). AR Wrocław.

Forutan M., Ansari Mahyari S., Baes C., Melzer N., Schenkel F.S., Sargolzae i M. (2018). Inbreeding and runs of homozygosity before and after genomic selection in North American Holstein cattle. BMC Genomics, 19: 98.

Gurgul A., Szmatoła T., Topolski P., Jasielczuk I., Żukowski K., Bugno-Po$\mathrm{n}$ i ew i e r s k a M. (2016). The use of runs of homozygosity for estimation of recent inbreeding in Holstein cattle. J. Appl. Genet., 57: 527-530.

Hen der s on C. (1975). Rapid method for computing the inverse of the relationship matrix. J. Dairy Sci., 58: 1727-1730.

$\mathrm{H}$ e n d e r s o n C. (1976). A simple method for computing the inverse of a numerator relationship matrix used in prediction of breeding values. Biometrics, 32: 69-83.

H ow ard J., Pry c e J., B a e s C., M a 1 te c c a C. (2017). Invited review: Inbreeding in the genomics era: Inbreeding, inbreeding depression, and management of genomic variability. J. Dairy Sci., 100: 6009-6024.

How ard D., Pong-Wong R., Knap P., Kremer V., Woolli a m J. (2018). Selective advantage of implementing optimal contributions selection and timescales for the convergence of longterm genetic contributions. Genet. Select. Evol., 50: 24.

Jag u siak W., Żarnecki A. (1994). Relationship and inbreeding in the population of Black and White sires used in artificial insemination (in Polish). Pr. Mat. Zoot., 46: 75-81.

J a g u s i a k W., Ż a r n e c k i A. (2002). Estimation of inbreeding and relationship among young Polish Black-and-White bulls. Proc. 7th World Congress on Genetics Applied to Livestock Production, Montpellier, France, 19-23.08.2002.

J a g u s i a k W., P ta k E. (2003). Inbreeding in the population of Polish Black and White cattle (in Polish). Rocz. Nauk. Zoot. Supl., 17: 377-380. 
James J., McBride G. (1958). The spread of genes by natural and artificial selection in closed poultry flock. J. Genet., 56: 55-62.

Kania-Gierdziewicz J. (2005). Inbreeding and relationship in Polish Black-and-White sires. J. Appl. Genet., 46: 187-193.

König S., Tsehay F., Sitzenstock F., von Borstel U.U., Schmutz M., Preis inger R., Simianer H. (2010). Evaluation of inbreeding in laying hens by applying optimum genetic contribution and gene flow theory. Poultry Sci., 89: 658-667.

Lutaaya E., Misztal I., B ertrand J., Maybry J. (1999). Inbreeding in populations with incomplete pedigrees. J. Anim. Breed. Genet., 116: 4475-4480.

M e u w is s e n T., L u o Z. (1992). Computing inbreeding coefficients in large populations. Genet. Sel. Evol., 24: 305-313.

Miglior F., Burnside E., Dekkers J. (1995). Production traits of Holstein cattle: Estimation of nonadditive genetic variance components and inbreeding depression. J. Dairy Sci., 78: 1174-1180.

O h S. (2012). Evaluation of optimum genetic contribution theory to control inbreeding while maximizing genetic response. Asian-Australas J. Anim. Sci., 25: 299-303.

Panet to J., Guti erres J., Ferraz J., Cunha D., Gold en B. (2010). Assessment of inbreeding depression in a Guzerat dairy herd: Effects of individual increase in inbreeding coefficients on production and reproduction. J. Dairy Sci., 93: 4902-4912.

Parland S., Kearney J., Rath M., B erry D. (2007). Inbreeding effects on milk production, calving performance, fertility, and conformation in Irish Holstein-Friesians. J. Dairy Sci., 90: 4411-4419.

Pavlik I., Kadlecik O., Huba J., P es kovicova D., Gondekova M. (2019). Genetic variability of Holstein cattle assessed by pedigree analysis. Slovak J. Anim. Sci., 52: 30-38.

PFHBiPM (2018). Krajowy program hodowlany dla bydła rasy Polskiej Holsztyńsko-Fryzyjskiej w Polsce (in Polish). Available from www.pfhb.pl (accessed 18.11.2018).

P o la k G. (2019). Genetic variability of cold-blooded horses participating in genetic resources conservation programs, using pedigree analysis. Ann. Anim. Sci., 19: 49-60.

Różańska-Zawieja J., Nienartowicz-Zdrojewska A., Mucha M., Sobek Z., Stanisławski D., Gierdziewicz M., Kania-Gierdziewicz J. (2013). Evaluation of inbreeding and relationship coefficients in Hovawart dogs and analysis of trends in coat colour changes. Ann. Anim. Sci., 13: 253-262.

S a n chez-Molan o E., P ong - Wong R., B an os G. (2016). Genomic-based optimum contribution in conservation and genetic improvement programs with antagonistic fitness and productivity traits. Front Genet., 7: 25.

Sell-Kubiak E., Czarniecki Ł., Strabel T. (2018). Challenges in inbreeding estimation of large populations based on Polish Holstein-Friesian cattle pedigree. J. Appl. Genet., 59: 313-323.

Sewalem A., Kistemaker G., Miglior F., Van Doormaal B. (2006). Analysis of inbreeding and its relationship with functional longevity in Canadian dairy cattle. J. Dairy Sci., 89: 3609-3614.

S m it h L., C a s s e 11 B., P e a r s o n R. (1998). The effects of inbreeding on the lifetime performance of dairy cattle. J. Dairy Sci., 81: 2729-2737.

Sorens en A., M a d s en P., S or en s e n M., B erg P. (2006). Udder health shows inbreeding depression in Danish Holsteins. J. Dairy Sci., 89: 4077-4082.

Strabel T. (2001). Reducing inbreeding in modern dairy farming (in Polish). Pr. Mat. Zoot., 59: 25-36.

Ś w i d e re k W., F is z d o n K., K a c pr z a k N. (2015). Inbreeding in Pembroke Welsh Corgi population in Poland. Ann. Anim. Sci., 15: 861-866.

Thompson J., Everet R., Hammers chmidt N. (2000). Effects of inbreeding on production and survival in Holsteins. J. Dairy Sci., 83: 1856-1864.

To p ols k i P. (2008). Insemination of cattle in 2007 (in Polish). IZ PIB, Kraków, 6, 36.

T o p o ls k i P. (2017). Inbreeding in dairy cattle (in Polish). Wiad. Zoot., LV: 31-38.

To polski P., Majews ka A. (2006). Insemination of cattle in 2005 (in Polish). IZ PIB, Kraków, 4, 36 . 
To p o ls ki P., J a g u s i a k W. (2011). Relatedness analysis in a population of Polish Black-and-White Holstein-Friesian bulls (in Polish). Rocz. Nauk. Zoot., 38: 169-176.

To p olski P., Jag u s i k W. (2012). Genetic background of conformation defects in Polish Blackand-White Holstein-Friesian bulls - analysis of phenotypic distribution. Ann. Anim. Sci., 12: 471482.

Tre la J., W ó j c i k P., A d a m i k P. (1995). Doskonalenie bydła czarno-białego przy użyciu buhajów odmiany niemieckiej (in Polish). Biul. Inf. IZ, 1: 17-28.

Van R a d e n P. (1992). Accounting for inbreeding and crossbreeding in genetic evaluation for large populations. J. Dairy Sci., 75: 3136-3144.

Wa 11 E., B rotherst o ne J., K e arne y J., W o o li a m s J., C offe y M. (2005). Impact of nonadditive genetic effects in the estimation of breeding values for fertility and correlated traits. J. Dairy Sci., 88: 376-385.

Wang Y., Sege 1 ke D., Emmerling R., B ennewitz J., We 11 mann R.. (2017). Long-term impact of opitmum contribution selection strategies on local livestock breeds with historical introgression using the example of German Angler cattle. G3 (Bethesda), 7: 4009-4018.

We ste 11 R., Qu a s R., Van V le ck L. (1988). Genetic groups in an animal model. J. Dairy Sci., 71: $1310-1318$.

Wigg an s G., Van R a d e n P., Z u u r b i e r J. (1995). Calculation and use of inbreeding coefficients for genetic evaluation of United States dairy cattle. J. Dairy Sci., 78: 1584-1590.

Wo olli a m s J., B erg P., Dagna chew B., M e uw is s en T. (2015). Genetic contributions and their optimization. J. Anim. Breed. Genet., 32: 89-99.

Young C., S e y k or a A. (1996). Estimates of inbreeding and relationship among registered Holstein females in the United States. J. Dairy Sci., 79: 502-505.

Received: 26 IV 2019

Accepted: 18 IX 2019 